\title{
COMBUSTION ANALYSIS OF A CNG DIRECT INJECTION SPARK IGNITION ENGINE
}

\author{
A. Rashid A. Aziz, Firmansyah and Raja Shahzad \\ Center for Automotive Research (CAR) \\ Mechanical Engineering Department, Universiti Teknologi Petronas \\ Bandar Seri Iskandar, 31750 Tronoh, Perak, Malaysia \\ Phone: +605-3654069, Fax: +605-3654086 \\ E-mail: rashid@petronas.com.my
}

\begin{abstract}
An experimental study was carried out on a dedicated compressed natural gas direct injection (CNG-DI) engine with a compression ratio (CR) of 14 and a central injection system. Several injection timing parameters from early injection timing ( $\left.300^{\circ} \mathrm{BTDC}\right)$ to partial direct injection $\left(180^{\circ}\right.$ BTDC) to full direct injection $\left(120^{\circ}\right.$ BTDC) were investigated. The $300^{\circ}$ BTDC injection timing experiment was carried out to simulate the performance of a port injection engine and the result is used as a benchmark for engine performance. The full DI resulted in a $20 \%$ higher performance than the early injection timing for low engine speeds up to $2750 \mathrm{rpm}$. $180^{\circ}$ BTDC injection timing shows the highest performance over an extensive range of engine speed because it has a similar volumetric efficiency to full DI. However, the earlier injection timing allowed for a better air-fuel mixing and gives superior performance for engine speeds above $4500 \mathrm{rpm}$. The engine performance could be explained by analysis of the heat release rate that shows that at low and intermediate engine speeds of 2000 and 3000, the full DI and partial DI resulted in the fastest heat release rate whereas at a high engine speed of $5000 \mathrm{rpm}$, the simulated port injection operation resulted in the fastest heat release rate.
\end{abstract}

Keywords: Compressed natural gas, direct injection, injection timing

\section{INTRODUCTION}

The use of natural gas in the transportation sector has been increasing over the years. This is further supported by the increasing concern on environmental problems and energy security. The development of natural gas as a fuel closely followed the growth of vehicle conversion from both gasoline- and diesel-fuelled engines to natural gas fuelled in many countries. Fueling systems are becoming critical parts in the vehicle conversion process (Kato et al., 1999; Catania et al., 2000). In the spark ignition (SI) engine category, fueling systems can be classified as carburetor, single/multi port injection, and direct injection. For natural gas vehicles, the first generation fueling system is the mixer system and this has progressed to the more sophisticated single- and multi-port injection systems. However, with natural gas as the fuel, spark ignition engine performance drops to $20 \%$ (Mello et al., 2006). It was also stated that the performance drop is due to lower volumetric and thermal efficiencies.

Despite the performance drop, natural gas had better exhaust emissions. It has less hydrocarbon and carbon monoxide compared to gasoline fuel. The lower CO emission of natural gas fuel was also confirmed by Pourkhesalian et al. (2009). They 
also stated that the BSFC of methane as fuels is lower compared to gasoline fuel. These potentials of natural gas as fuels need to be improved further. The highest obstacle of natural gas to be implemented for a wide range of applications is the engine power output. The gaseous phase of natural gas has the advantage of a faster mixing rate. However, the gaseous phase is also the main cause of lower volumetric efficiency. In order to reduce this effect, recent investigations in natural gas engines are looking at the direct injection system as a possibility for the fourth generation fueling system to increase the natural gas engines' performance. A direct injection system is expected to increase the volumetric efficiency of the natural gas engine and is able to operate in lean conditions.

The feasibility of implementing direct injection systems in $\mathrm{CNG}$ engines has been investigated by a few researchers. Huang et al. (2003a) discussed the possibility of a direct injection system in a CNG engine using a rapid compression machine (RCM) with a $10 \mathrm{CR}$ and observed that the injection timing significantly affected the intensity of fuel stratification before ignition which in turn affects the combustion behaviour of a CNG-DI engine. Hayashida et al. (1999) proved that injection timing could increase engine volumetric efficiency and brake power while the best fuel air mixing occur with the injection events around inlet valve closing (IVC): later confirmed by Zeng et al. (2006). Wang and Watson (2000) had shown that direct injection of CNG has lower hydrocarbon emission compared to port injection. These previous investigations had led to the notion that controlling the injection timing in a direct injection system could further increase the $\mathrm{CNG}$ engine performance. However, these previous researchers conducted their experiment on either a rapid compression machine or a converted gasoline fuelled engine in which the compression ratio was maintained near the knock limiting value of gasoline. In order to fully utilize the capability of CNG fuel, which has a higher knock limit, the present research was conducted on a dedicated engine with a compression ratio of 14 . The objectives of this research are to investigate the effect of injection timing on the performance, emissions and combustion behaviour of the CNGDI engine. The results of varying the injection timing on the performance of a CNG-DI engine at wide-open throttle (WOT) and a wide range of engine speeds are presented.

\section{MATERIALS AND METHODS}

\section{Experimental Procedure}

This research was based on the experimental study conducted at the Centre for Automotives Research (CAR) in Universiti Teknologi PETRONAS (UTP). The test conducted follows the SAE standard on engine performance and emission testing. The experimental set up is shown in Figure 1. Wide-open throttle is specified in this experiment as representative of full load condition. The equivalence ratio was kept constant at 1.0, and the ignition timing was adjusted via the engine control unit (ECU) to obtain the best torque reading (MBT). The engine speed range was 2000-5000 rpm. The injection timing was varied from a very early injection timing at $300^{\circ}$ BTDC (intake valve starting to open at $372^{\circ}$ BTDC) to a late injection timing at $120^{\circ}$ BTDC (intake valve close at $132^{\circ} \mathrm{BTDC}$ ). In Figure 2, the early injection timing with the start of injection (SOI) at $300^{\circ} \mathrm{BTDC}$ is to simulate port injection fueling system. At an SOI of $180^{\circ} \mathrm{BTDC}$, a partial direct injection was achieved where the injection starts while the intake valve is open and ends after the intake valve is closed. The full DI is achieved 
for injection events after the intake valve closed. It should be noted that full DI is limited by the ignition timing for safety reasons. Hence, in our investigation, all injection events were completed before ignition occurred. All the experiments were conducted with a stable operation with a $5 \%$ COV of IMEP.

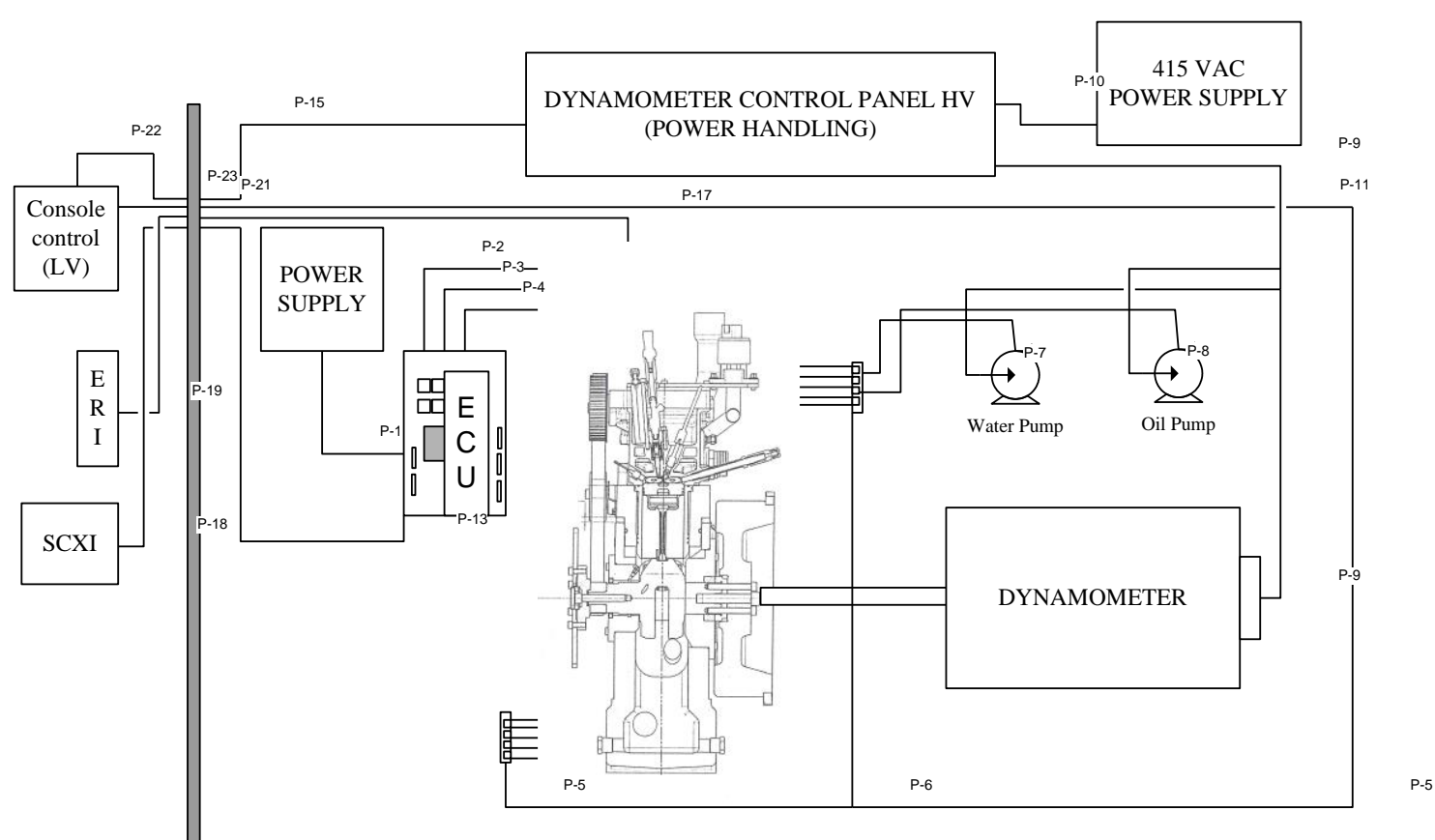

Figure 1. Experimental set up

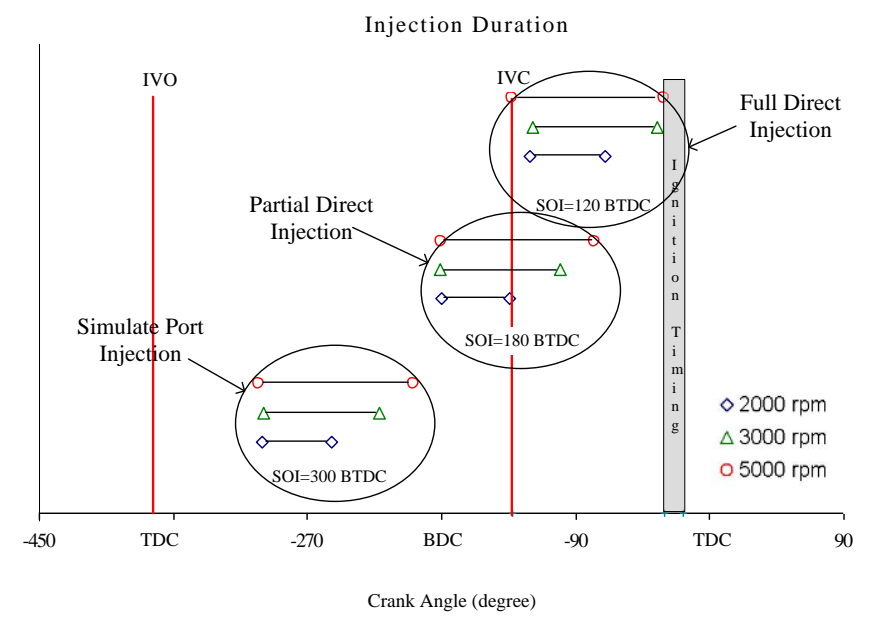

Figure 2. Injection timing characterization

\section{Equipment}

The engine used in this experiment is a four-stroke spark ignition single cylinder research engine. Table 1 elaborates the specification of the experimental engine. A fuel pressure regulator was used to control the fuel rail pressure and stabilize the injector pressure. Engine control parameters such as injection timing, ignition timing and airfuel ratio were controlled via the engine control unit (ECU). Figure 3(a) shows the 
injector position relative to the intake and exhaust valve. The injector is positioned at the centre of the combustion chamber between the intake and exhaust valve while Figure 3(b) shows the injector position relative to the spark plug position, which is slightly offset at an angle. A modified long tip spark plug was used in order to reach deeper into the combustion zone to assure combustion of the CNG fuel. Table 3 highlights the fueling system designed for CNG operation for a fuel rail pressure of 18 bar. The fuel rail pressure is adjustable from 8 to 20 bar, with a supply from a CNG tank pressurized at 200 bar. Commercially available CNG fuel was used in this experiment. The CNG composition in Malaysia is given in Table 3, referring to the datasheet given by PETRONAS.

Table 1. Engine Specifications

\begin{tabular}{ll}
\hline & Engine Specification \\
\hline Manufacturer & G. Cussons Ltd \\
Type & Ricardo Hydra MK IV \\
ECU software & Orbital. Inc \\
No. of Cylinder, Strokes & Single cylinder, Four stroke \\
Fuel & Compressed Natural Gas \\
Bore and Stroke & $88 \mathrm{~mm}$ and 132 mm \\
Compression ratio & 14 \\
Exhaust Valve open (EVO) & $45^{\circ} \mathrm{BBDC}$ \\
Exhaust Valve Closed (EVC) & $10^{\circ} \mathrm{ATDC}$ \\
Inlet Valve Open (IVO) & $12^{\circ} \mathrm{BTDC}$ \\
Inlet Valve Closed (IVC) & $48^{\circ} \mathrm{ABDC}$ \\
\hline \multicolumn{2}{c}{ Dynamometer } \\
\hline Manufacturer & McClure \\
Type & Shunt wound de machine with separate excitation \\
Rating & $30 \mathrm{~kW}$ continuous absorbing \\
Max. Speed & $100 \mathrm{rev} / \mathrm{sec}$ \\
\hline \multicolumn{2}{c}{ Pressure Measurement and Data acquisition } \\
\hline Pressure transducer & Kistler \\
Manufacturer & Water cooled ThermoCOMP 6061B \\
Type & $0-250$ bar \\
Range & $25 \mathrm{pC} / \mathrm{bar}$ \\
Sensitivity & \\
Data acquisition system & LabView \\
Program & $10 \mathrm{kHz}$ \\
Frequency & $1 \mathrm{deg}$ \\
Crank angle accuracy &
\end{tabular}




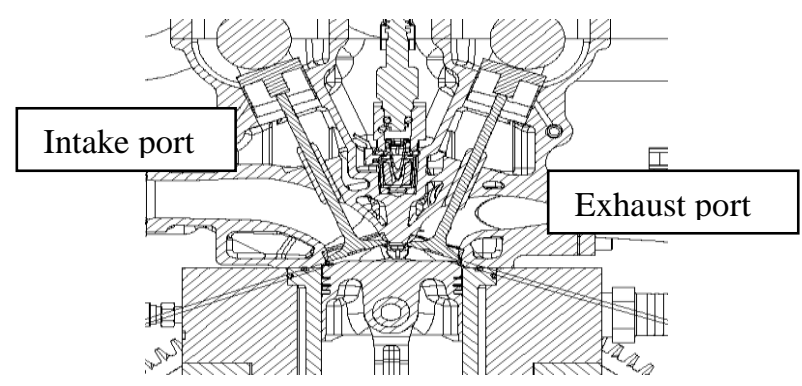

(a) Intake and exhaust port position

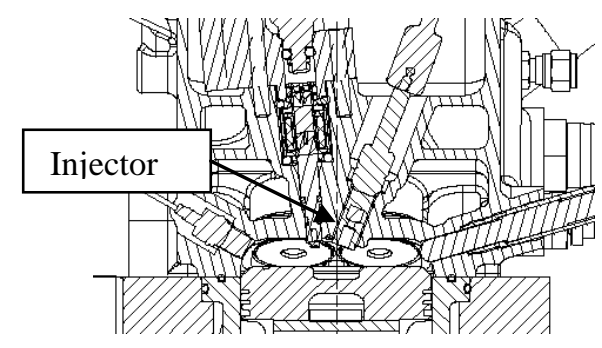

(b) Injector and Spark position

Figure 3. Engine cylinder head section

Table 2. Fuel system specification

\begin{tabular}{ll}
\hline \multicolumn{2}{c}{ Fuel System Specification } \\
\hline Type & Spray guided system \\
Rail Pressure & 18 bars \\
Injector & Central Direct \\
Position & Injection \\
\hline
\end{tabular}

Table 3. CNG composition in Malaysia

\begin{tabular}{lccc}
\hline Component & Leanest & Unit & Richest \\
\hline Methane & 96.42 & $\%$ & 89.04 \\
Ethane & 2.29 & $\%$ & 5.85 \\
Propane & 0.23 & $\%$ & 1.28 \\
Iso-Butane & 0.03 & $\%$ & 0.14 \\
N-Butane & 0.02 & $\%$ & 0.10 \\
Iso-Pentane & N/A & $\%$ & N/A \\
N-Pentane & N/A & $\%$ & N/A \\
N-Hexane & N/A & $\%$ & N/A \\
Condensate & 0.00 & $\%$ & 0.02 \\
Nitrogen & 0.44 & $\%$ & 0.47 \\
CO 2 & 0.57 & $\%$ & 3.09 \\
Gross Heating Value & 38130 & $\mathrm{~kJ} / \mathrm{kg}$ & 38960 \\
\hline
\end{tabular}

\section{Data Analysis}

The combustion analysis was done using the Rassweiler-Withrow method due to the advantage of this method in high speed data acquisition.

In general, the equation governing this method is

$$
\frac{d Q_{n}}{d \theta}=\left[\frac{1}{\gamma-1}\right] V \frac{d P_{C}}{d \theta}
$$


where: $\quad Q_{n}=$ Net heat release

$P_{c}=$ Pressure rise due to combustion $(\mathrm{kPa})$

$V=$ Total cylinder volume $\left(\mathrm{m}^{3}\right)$

$\gamma=$ Polytropic index

$$
\frac{d P_{c}}{d \theta}=P_{j}-P_{j-1}\left[\frac{V_{j-1}}{V_{j}}\right]^{\gamma}
$$

where: $\quad P_{j}=$ Pressure at $j$ crank angle

$V_{j}=$ Volume at $j$ crank angle

From the results of heat released calculation, the total heat released by the combustion process can be calculated as the sum of the instantaneous heat released every crank angle. The combustion efficiency can be calculated by dividing the total heat released by the total heat supplied by the fuel by the following equation:

$$
\eta_{c}=\frac{Q_{\text {out }}}{Q_{\text {in }}}=\frac{\sum Q_{c h}}{m_{f} q_{H V}}
$$

where $\Sigma Q_{c h}$ is the total heat released by the combustion process, $m_{f}$ is the fuel mass, and $q_{H V}$ is the specific heating value of fuel. The combustion stage is defined according to difference between the first derivation of pressure $(d P)$ on combustion and motoring pressure to determine the beginning and the end point of combustion process.

$$
\%=\frac{d P_{c}}{d P_{m}}=\frac{d P_{f}-d P_{m}}{d P_{m}}
$$

where $d P_{f}$ is the pressure during the power stroke, $d P_{c}$ is the pressure due to combustion and $d P_{m}$ is the pressure during motoring. Combustion begins if the difference between pressure due to combustion and motoring is $0 \%-5 \%$ and ends with the difference > $99 \%$.

\section{RESULTS AND DISCUSSION}

The effects of varying the injection timing on the CNG-DI engine are shown in Figure 4 and 5. The engine performance is presented in terms of torque, power, BMEP, and BSFC to describe the engine output for various injection timing conditions. At lower engine speed, the full DI resulted in 10\%-20\% higher torque compared to early injection timing. The maximum torque was achieved by DI for engine speeds below $2750 \mathrm{rpm}$. However, early injection timing resulted in a better torque at engine speeds above $4500 \mathrm{rpm}$. Partial DI and full DI resulted in $15 \%$ higher power compared to the $300^{\circ}$ BTDC for speeds of less than $2750 \mathrm{rpm}$. As the engine speed increases to 3500 $\mathrm{rpm}$, the performance of the engine with $120^{\circ}$ BTDC injection timing drops below that of $180{ }^{\circ} \mathrm{BTDC}$ injection timing. Engine performance with $180{ }^{\circ} \mathrm{BTDC}$ injection timing dominates until the speed of $4500 \mathrm{rpm}$ where the performance drops to $5 \%$ below early 
injection timing $\left(300^{\circ} \mathrm{BTDC}\right)$. At $5000 \mathrm{rpm}$ engine speed, the maximum torque was achieved by early injection timing. Hence, the torque characteristics of this engine can be controlled by using full DI operation for engine speed below $2750 \mathrm{rpm}$, using partial DI injection at $180^{\circ}$ BTDC for engine speeds between 2750 and $4500 \mathrm{rpm}$ and using early injection timing (similar to port injection operation) for engine speeds above 4500 rpm.

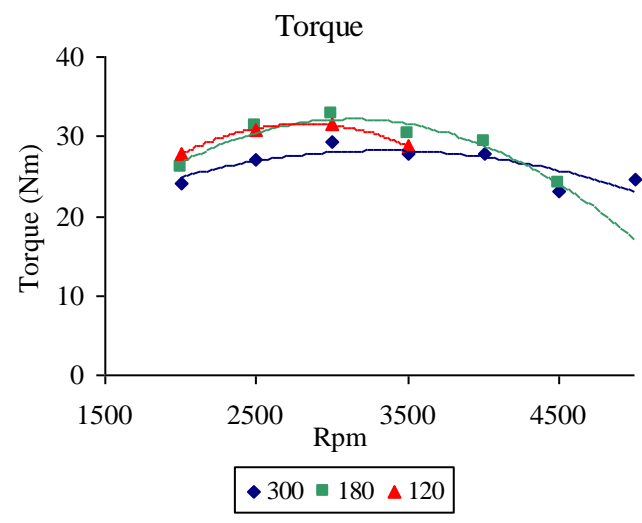

(a)

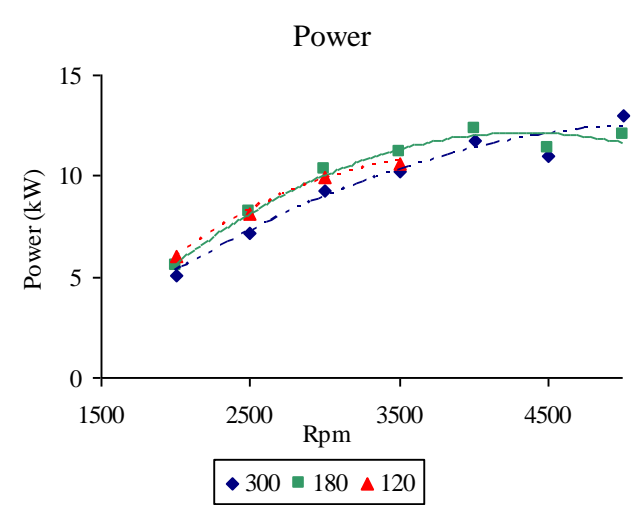

(b)

Figure 4. Engine performance in terms of torque and power

The BMEP results in Figure 5(a) follow closely the torque curve profile. The maximum value of $1040 \mathrm{kPa}$ is achieved at $3000 \mathrm{rpm}$ with $180^{\circ} \mathrm{BTDC}$ injection timing, and reduces to $750 \mathrm{kPa}$ at $5000 \mathrm{rpm}$ for injection timing of $300^{\circ} \mathrm{BTDC}$. Figure (b) represents the specific fuel consumption (BSFC) for this engine. The lowest BSFC was achieved by the injection timing of $120^{\circ}$ BTDC, up to the engine speed of $3000 \mathrm{rpm}$. Beyond $3000 \mathrm{rpm}, 180^{\circ} \mathrm{BTDC}$ injection timing gives the lowest BSFC value. At engine speeds above $4500 \mathrm{rpm}$, the BSFC value is about $2 \%$ lower than that given by the operation with $300^{\circ} \mathrm{BTDC}$ injection timing.

The different torque and power output of full DI, partial DI and port simulated are mainly due to the effect of volumetric efficiency. This can be observed in Figure 6. The volumetric efficiency shows an increasing trend as the injection timing is retarded. Full DI of $120^{\circ}$ has a higher volumetric efficiency (0.83-0.94) compared to partial DI $180^{\circ} \mathrm{BTDC}$ and early injection timing at $300^{\circ} \mathrm{BTDC}$ respectively. These results agree with the results from Zeng et al. (2006) where the increasing volumetric efficiency may be due toa lesser disturbance to the intake flow as the injection timing is retarded. According to Zeng et al. (2006), the pressure will increase due to the injection process. The increase of in-cylinder pressure will reduce the pressure difference between incylinder and atmospheric and in the end it will reduce the intake velocity. Reduced intake velocity will reduce the amount of air entering the cylinder for a given time space during the intake strokes. The performance of the engine is significantly affected by the volumetric efficiency at engine speeds below $4500 \mathrm{rpm}$. Within this range of engine speed, full DI and partial DI givs higher power output. Furthermore, partial DI has the combined effect of high volumetric efficiency with sufficient mixing time that gives a maximum engine performance between 2750 and $4500 \mathrm{rpm}$. At engine speeds above $4500 \mathrm{rpm}$, injection timing has less effect on the volumetric efficiency as shown in Figure 6 since less time is available for the intake stroke to gasp the air. Better mixing 
of port simulated injection has giving a better torque and power output for this engine speed.

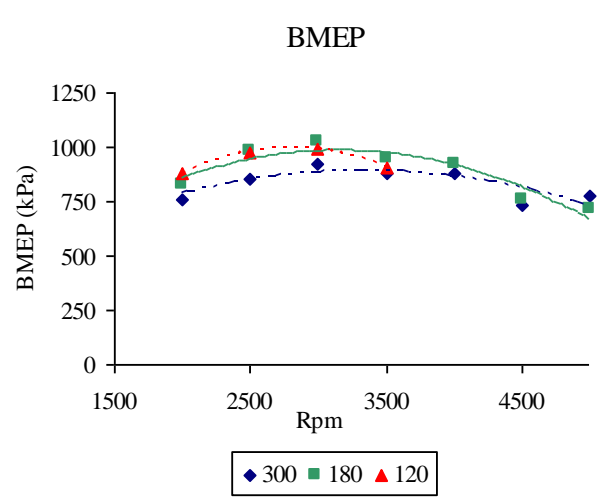

(a)

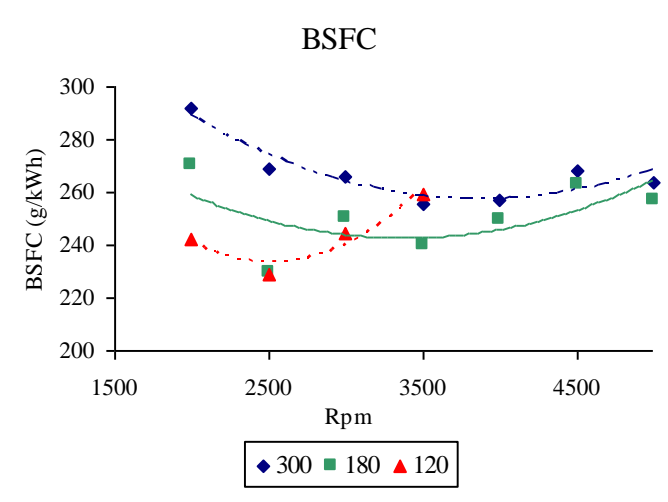

(b)

Figure 5. Engine performance in terms of BMEP and BSFC

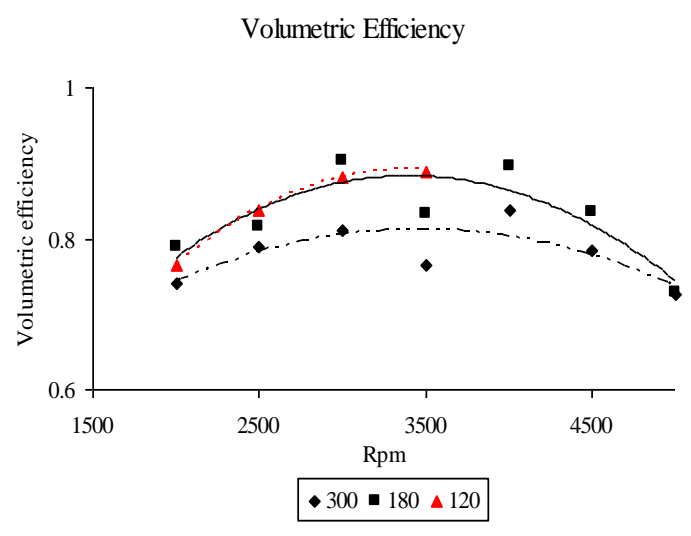

Figure 6. Volumetric efficiency for various injection timing

Figure 7 shows the emissions of NOx and $\mathrm{CO}$ for the CNG-DI engine as functions of the injection timing. At engine speeds below $3000 \mathrm{rpm}$, the operation with full DI resulted in the highest NOx and lowest CO levels. A higher level of NOx emission indicates a higher combustion temperature as the nitrogen content in the air will only experience break-up to create NOx if the temperature of the combustion is above $2000{ }^{\circ} \mathrm{C}$. A higher combustion temperature indicates that a better combustion process occurs inside the cylinder. Another indicator of good combustion is lower CO emissions, which occur due to the incompleteness of the combustion process. Furthermore, these results were confirmed by the pressure reading of full DI which shows the highest results compared to other injection timings as shown by Figure 7 . It can be concluded that full DI gives better combustion at a $2000 \mathrm{rpm}$ engine speed. At engine speeds above $3500 \mathrm{rpm}$, CO production is almost equal for partial and port simulated DI. However, NOx production is higher for partial DI thanks to better combustion as also shown in the combustion analysis. 


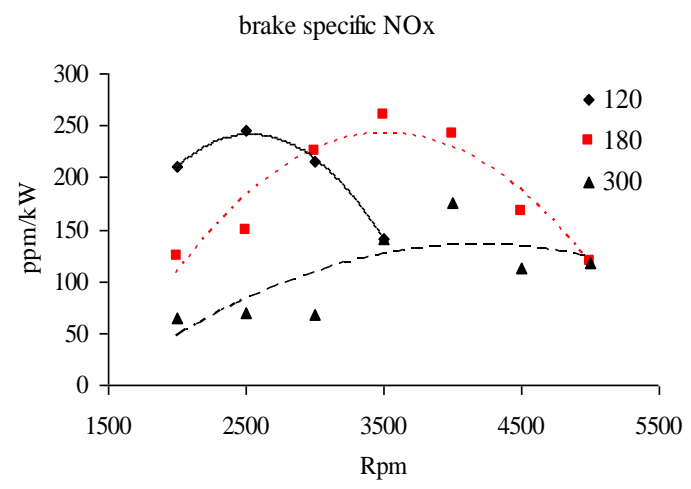

(a)

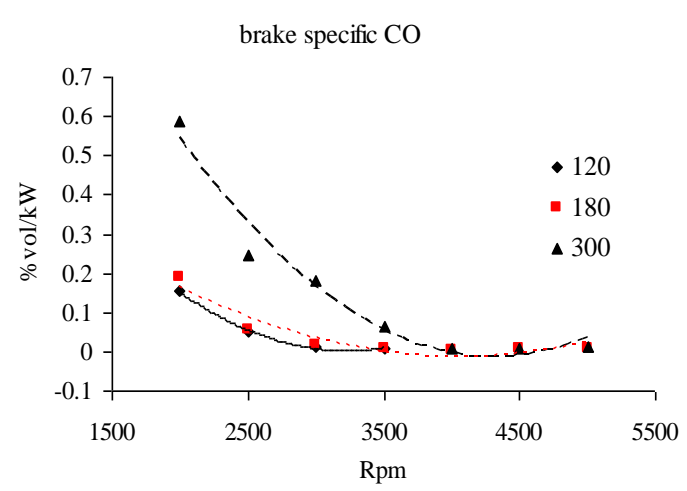

(b)

Figure 7. Engine emissions for various injection timing

Injection timing has a significant effect on the combustion process of $\mathrm{CNG}$ in a DI system. From the experimental results, each type of injection timing was optimized for a specific operating condition. Late injection timing (full DI) has better combustion results at $2000 \mathrm{rpm}$ as shown in Figure 8(a). The maximum pressure for full DI reaches 59 bars which is higher than other injection timings. The better combustion with a full DI system might be due to a higher turbulence level in the combustion chamber that is indicated by a faster heat release rate, especially for $10 \%-90 \%$ of the combustion process (Figure 8b). A faster duration of the primary stage of the combustion process is also shown in Figure 8(c) where full DI systems show faster burning periods compared to other injection timings. The partial DI process has a similar burning rate to that of the port simulated, but with higher combustion efficiency: close to full DI's result. The higher peak pressure and shorter combustion duration shown by full DI in Figure 8(f) may due to the higher turbulence intensity at the main combustion stage. A similar result was reported by Wang et al. (2008) in an experiment with a constant volume chamber. Furthermore, the initial combustion stage (Figure 8f) and the ignition delay period (Figure 8e) of full DI is faster than those of the other injection timings, which strongly indicates the existence of high charge stratification using full DI system in the combustion chamber (Huang et al., 2003b). Thus, high charge stratification and faster combustion duration lead to better combustion efficiency for partial DI and full DI. However, these lower engine speed results are somewhat different from the results shown by Zeng et al. (2006). In their report, $180^{\circ}$ BTDC injection timing has the highest maximum pressure compared to other injection timings, earlier or later. These differences may be due to a higher injection pressure at lower compression ratios for a lean mixture of CNG.

Partial direct injection $\left(180^{\circ} \mathrm{BTDC}\right)$ has better performance than other injection timings at $3000 \mathrm{rpm}$ where it shows the highest maximum pressure which is about 75 bars (Figure 9a). The maximum pressure occurs due to better combustions inside the chamber. This argument is also supported by the highest heat released rate from partial DI timing compared to full-DI and port simulated injection timing (Figure 9b) with 0.07 $\mathrm{kJ} / \mathrm{CA}$. Mass fraction burned results on Figure 9(c) shows that partial DI results in a slightly higher burn rate than full DI and significantly higher than port simulated injection. Injection timings have the least effect on the heat release rate at the start of combustion $(0 \%-10 \%)$. However, the trend changes as combustion progresses: partial DI and full DI show faster heat release rate for $10 \%-90 \%$, which indicates that a high 
intensity of turbulence occurs inside the cylinder. Furthermore, partial DI obtained better combustion efficiency (Figure 9d) compared to other injection timings due to a lower ignition delay combined with a shorter combustion duration.

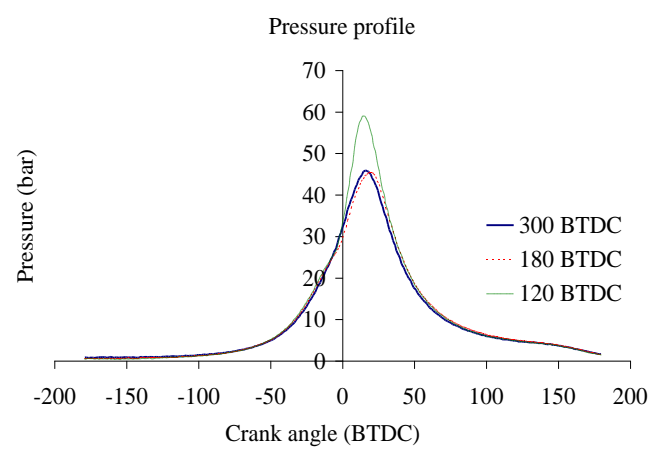

(a)

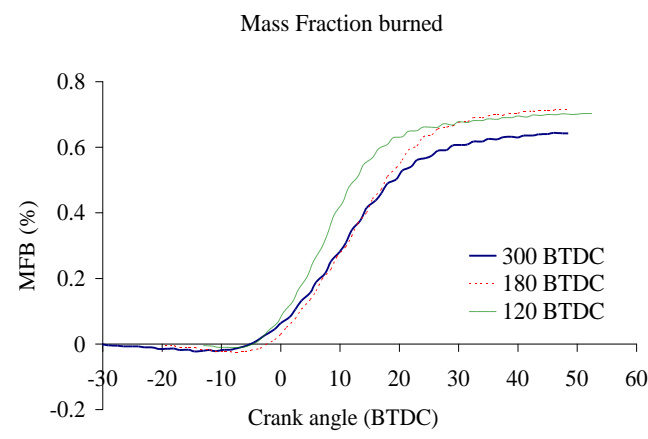

(c)

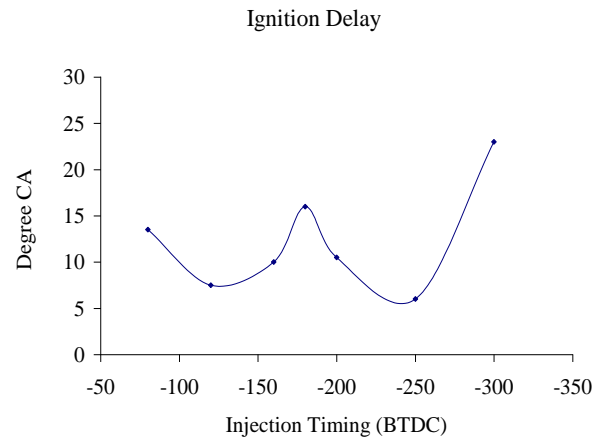

(e)

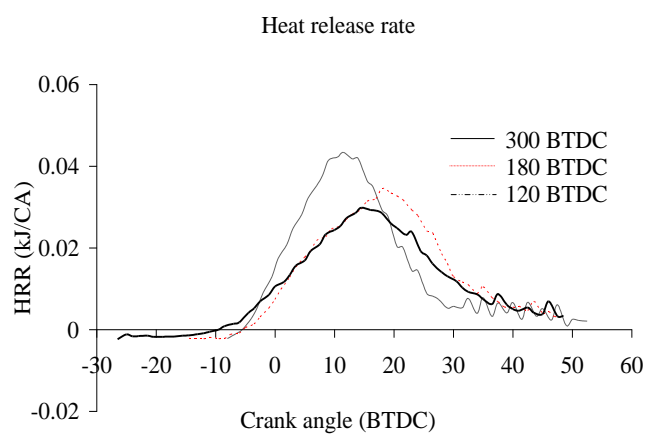

(b)

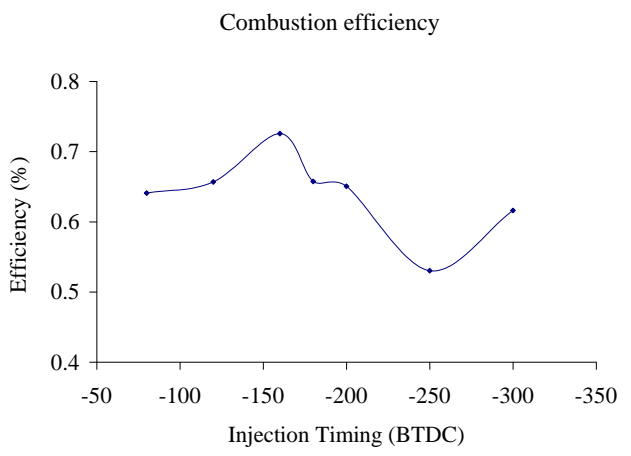

(d)

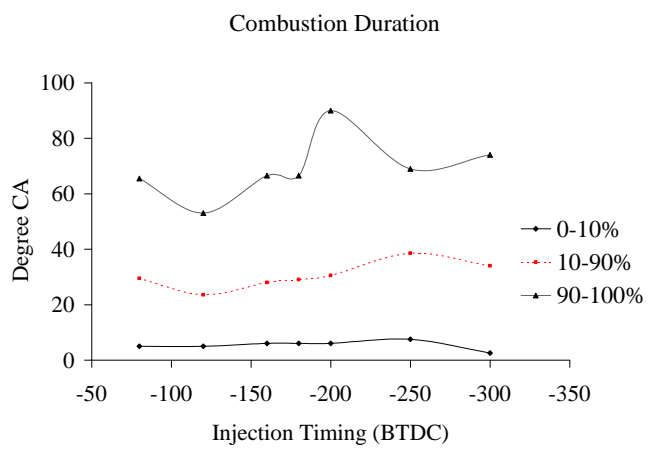

(f)

Figure 8. Combustion analysis for various injection timings at $2000 \mathrm{rpm}$ : (a) Pressure profile (b) Heat release rate (c) Mass fraction burned (d) Combustion efficiency (e) Ignition delay (f) Combustion duration

Ignition delay is shown in Figure 9(e): the ignition delay decreases steeply as the injection timing is retarded from port simulated injection to partial DI. However, the ignition delay has only a small increment if the injection timing continues to retard. This decreasing delay may be due to increasing charge stratification levels around the spark at the ignition. As stated by Huang et al. (2003b), ignition delay at the engine is highly affected by the equivalence ratio around the spark during the ignition; a lower ignition delay indicates that a rich mixture is created at the spark during ignition. Small 
differences in ignition delay of partial and full DI may indicate that the mixture stratification level of partial and full DI is similar. But the main combustion stage, from $10 \%-90 \%$, is mostly affected by the intensity of turbulence inside the chamber. Turbulence proved to affect the flame propagation in the SI engine. Higher turbulence levels can increase the flame velocity in an SI engine and shorten the combustion duration. Full DI shows the shortest duration among all the injection timings, while partial DI and port simulated injection have longer durations, consecutively (Figure 9f). It is shown that full DI creates a higher turbulence intensity compared to other injection timings. A homogeneous mixture of port simulated DI at $3000 \mathrm{rpm}$ causes the longer ignition delay and it also has a low turbulence intensity which increases the combustion duration. In the end, these results produce lower combustion efficiency.

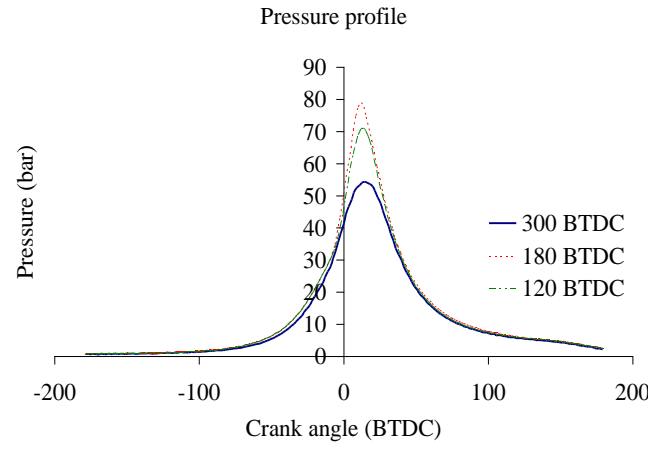

(a)

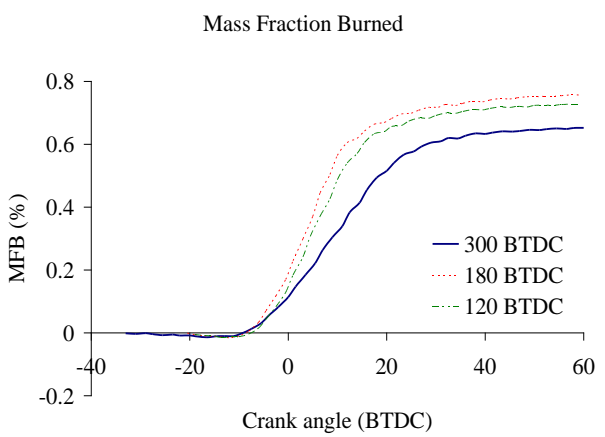

(c)

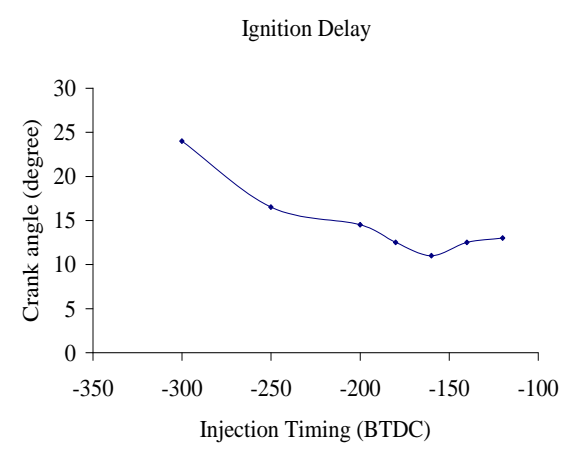

(e)

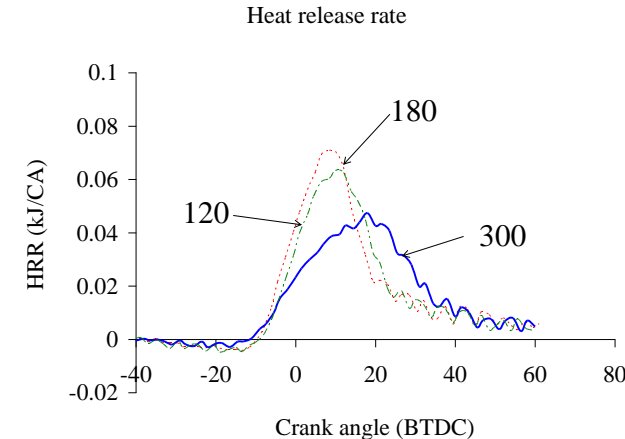

(b)

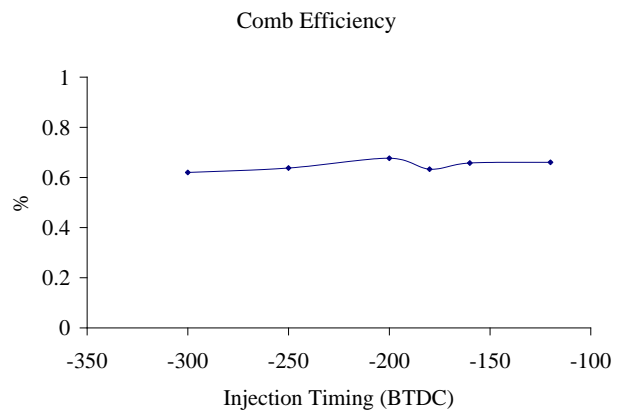

(d)

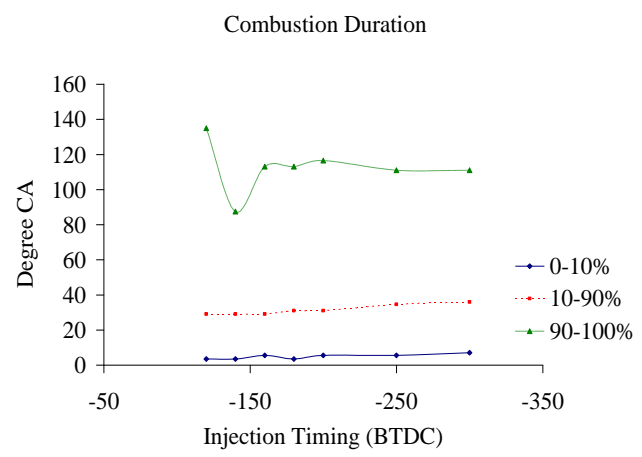

(f)

Figure 9. Combustion analysis for various injection timings at $3000 \mathrm{rpm}$ : (a) Pressure profile (b) Heat release rate (c) Mass fraction burned (d) Combustion efficiency (e)

Ignition delay (f) Combustion duration 


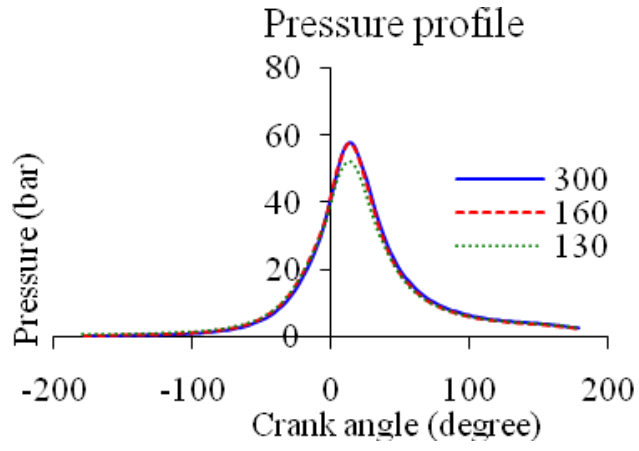

(a)

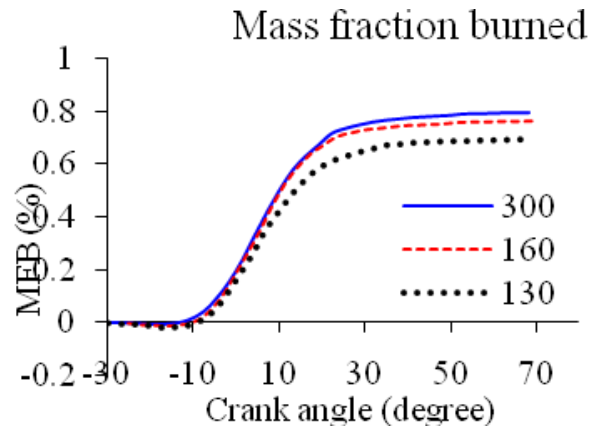

(c)

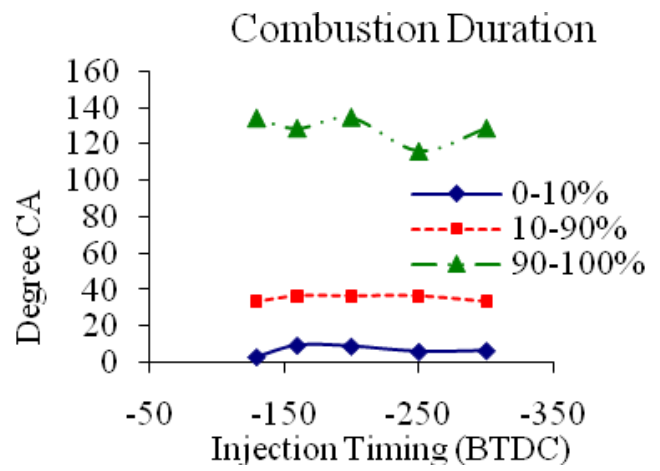

(e)

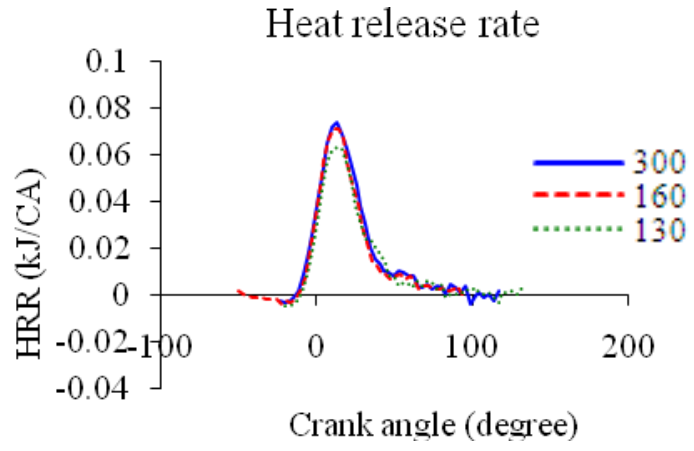

(b)

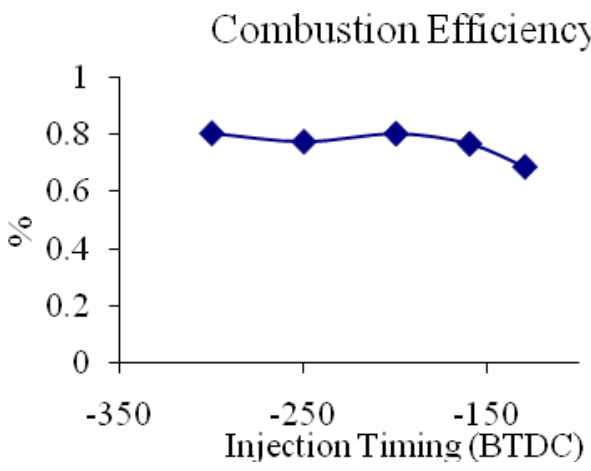

(d)

Ignition Delay

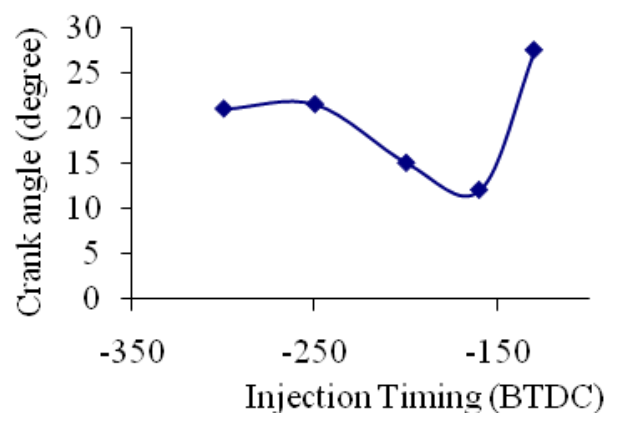

(f)

Figure 10. Combustion analysis for various injection timings at $5000 \mathrm{rpm}$ : (a) Pressure profile (b) Heat release rate (c) Mass fraction burned (d) Combustion efficiency (e)

Ignition delay (f) Combustion duration

Port simulated injection (injection at $300^{\circ}$ BTDC) has better combustion at high rpm $(5000 \mathrm{rpm})$. The peak cylinder pressure is almost the same as that obtained from partial DI timing, which is 57 bars as seen in Figure 10(a), while full DI gives a lower pressure of 40 bars. At high engine speeds, the occurrence of a high degree of fuel stratification, which also indicates incomplete mixing, as possessed by full DI, is not a favourable condition for the combustion process as it causes incomplete mixing and high cycle-to-cycle variation, as also shown by lower maximum pressure. Better combustion with port simulated and partial DI timing can be seen in the heat release rate graph (Figure 10b) where both injection timings have higher maximum heat released $(0.075 \mathrm{~kJ} / \mathrm{CA})$ compared to full DI $(0.06 \mathrm{~kJ} / \mathrm{CA})$. Full DI shows a low maximum heat 
released, indicating that the combustion process is inferior compared to other injection timings. Figure10(b) also shows that full DI has drift in the maximum heat released which is at $25^{\circ}$ ATDC due to a slower duration of the end of the combustion stage (90\%-100\%).

The delay is clearly seen in the mass fraction burned (Figure 10c), where full DI starts to combust a few degrees before TDC, and has reduced combustion efficiency. Further, combustion efficiency decreases as the injection timing is retarded, from $0.8 \%$ to $0.68 \%$ (Figure 10d), while port simulated injection has a similar MFB as partial DI. Figure 10(d) shows that combustion efficiency is decreasing as the injection timing is retarded. A different trend has been shown by the effect of injection timing on combustion efficiency compared to lower engine speeds. This shows that at high engine speed, the mixing window is important. Bigger mixing window gives better combustion at high speed. The combustion duration for all injection timings does not give much difference for the 0\%-90\% combustion stage (Figure 10e). But it decreases as the injection timing is advanced for the combustion stage $90 \%-100 \%$. These ignition delay results shows that the delay period is decreased as the injection timing is retarded from port simulated to partial DI timing, but increases steeply when full DI is applied (Figure 10f). These results show that port simulated injection timing is the most suitable for high engine rpm as compared to partial DI and full DI operations.

\section{CONCLUSIONS}

The following conclusions can be drawn on the effect of injection timing on the performance and combustion of a CNG-DI engine:

- Full DI $\left(120^{\circ}\right.$ BTDC) increases the volumetric efficiency of the engine and gives better performance at engine speeds below $2750 \mathrm{rpm}$. Moreover, full DI has a higher heat release rate, better combustion efficiency and faster combustion duration at $2000 \mathrm{rpm}$ due to higher charge stratification.

- Partial injection timing at $180^{\circ}$ BTDC resulted in a good performance for engine speeds between $2750-4500 \mathrm{rpm}$ because of the slight difference on volumetric efficiency compared to $120^{\circ}$ BTDC injection timing. Higher homogeneity compared to full DI with additional charge stratification due to injection after IVC leads to the better combustion results of partial DI which is shown by its higher heat release rate, faster combustion duration and higher combustion efficiency at $3000 \mathrm{rpm}$.

- At engine speeds above $4500 \mathrm{rpm}$, early injection timing at $300^{\circ} \mathrm{BTDC}$ resulted in the highest engine performance due to complete mixing of the air and fuel, in spite of the lower volumetric efficiency.

At engine speeds below $3000 \mathrm{rpm}$, NOx emission increased and $\mathrm{CO}$ emission decreased with retarding of injection timing, indicating a higher combustion temperature and a more complete combustion. This could be attributed to a higher air volume per cycle and increased turbulence due to the DI operation.

- At engine speeds above $3500 \mathrm{rpm}$, the level of CO production is almost invariant with injection timing. However, NOx production is higher for the partial injection timing of $180^{\circ} \mathrm{BTDC}$ compared to early injection at $300^{\circ} \mathrm{BTDC}$, indicating a higher combustion temperature. This could be due to the higher volumetric efficiency that resulted in more air volume per cycle and a higher effective compression ratio. 
- At the intermediate engine speeds of 2000 and $3000 \mathrm{rpm}$, full DI and partial DI operations result in the fastest rate of heat release while at the high engine speed of $5000 \mathrm{rpm}$, port-injected equivalent operation results in the fastest rate of heat release.

\section{ACKNOWLEDGEMENTS}

The author would like to acknowledge the funding support for the experimental facilities from the Ministry of Science, Technology and Innovation (MOSTI) of Malaysia (03-02-02-0057-PR0030/10-04) and Universiti Teknologi PETRONAS.

\section{REFERENCES}

Catania, A.E., Misul, D., Spessa, E. and Martorana, G. (2000) Conversion of a Multivalve Gasoline Engine to run on CNG. SAE Technical Paper, No. 200001-0673.

Huang, Z., Shiga, S., Ueda, T., Nakamura, H., Ishima, T., Obokata, T., Tsue, M. and Kono, M. (2003b) Effect of Fuel Injection Timing Relative to Ignition Timing on the Natural-gas Direct-Injection Combustion. Journal of Engineering for Gas Turbines and Power ASME, 217: 53-61.

Huang, Z., Shiga, S., Ueda, T., Nakamura, H., Ishima, T., Obokata, T., Tsue, M. and Kono, M. (2003a) Combustion Characteristics of Natural Gas Direct Injection Combustion Under Various Fuel Injection Timings. Proceedings of the Institution of Mechanical Engineers, Part D: Journal of Automobile Engineering, 217: 935-941.

Hayashida, M., Yamato, T., Sekino, H. and Sugahara, K. (1999) Investigation of Performance and Fuel Distribution of a Direct Injection Gas Engine Using LIF Measurement. SAE Paper, No. 1999-01-3291.

Kato, K., Igarashi, K., Masuda, M., Otsubo, K., Yasuda, A., Takeda, K. and Sato, T. (1999) Development of Engine for Natural Gas Vehicle. SAE Paper, No. 199901-0574.

Mello, P., Pelliza, G., Cataluna, R. and Silva, D.R. 2006. Evaluation of the maximum horse power of vehicles converted for use with natural gas fuel. Journal of Fuel, 85: 2180-2186.

Pourkhesalian, A.M, Samekhi, A.H. and Salimi, F. (2009) Alternative Fuel and Gasoline in an SI Engine: A Comparative Study of Performance and Emissions Characteristics. Journal of Fuel. 89(5): 105-1063.

Wang, D.E. and Watson, H.C. (2000) Direct Injection Compressed Natural Gas Combustion and Visualization. SAE, 2000-01-1838.

Wang, J., Huang, Z., Miao, H., Wang, X. and Jiang, D. (2008) Characteristics of Direct Injection Combustion Fuelled by Natural Gas-Hydrogen Mixtures Using a Constant Volume Vessel. International journal of Hydrogen Energy, 33: 19471956.

Zeng, K., Huang, Z., Liu, B., Liu, L., Jiang, D., Ren, Y. and Wang, J. (2006) Combustion Characteristics of a Direct-Injection Natural Gas Engine Under Various Fuel Injection Timings. Journal of Applied Thermal Engineering, 26: 806-813. 